\title{
Magnitude and Pattern of Caesarean Sections in a Teaching Hospital, Northwest Nigeria: A 5 Year Analysis
}

\author{
I. S. Abubakar ${ }^{1,3, ~ *}$, A. Rabiu ${ }^{1,3}$, A. D. Mohammed ${ }^{2,3}$ \\ ${ }^{1}$ Department of Obstetrics and Gynaecology, Bayero University, Kano, Nigeria \\ ${ }^{2}$ Department of Anesthesiology and Intensive Care, Bayero University, Kano, Nigeria \\ ${ }^{3}$ Aminu Kano Teaching Hospital, Kano, Nigeria
}

Email address:

idi.sulaiman@gmail.com (I. S. Abubakar)

\section{To cite this article:}

I. S. Abubakar, A. Rabiu, A. D. Mohammed. Magnitude and Pattern of Caesarean Sections in a Teaching Hospital, Northwest Nigeria: A 5 Year Analysis. Journal of Gynecology and Obstetrics. Vol. 3, No. 2, 2015, pp. 26-28. doi: 10.11648/j.jgo.20150302.12

\begin{abstract}
Background: The pattern of Caesarean section rate is on the rise with emergency surpassing elective caesarean deliveries. This could not be unconnected to the safety of anaesthesia in modern obstetrics. Method: Data on Caesarean deliveries conducted from January, 2005 to December, 2009 was analyzed using Epi Info Statistical Software. Results: The Caesarean section rate was $18.75 \%$. The mean age was $28.02 \pm 5.86$ years. Emergency Caesarean section was the majority $(59.4 \%)$ while the remaining (40.6\%) were elective. General anaesthesia was used for the majority (66.68 \%) of the cases, while $33.32 \%$ had subarachnoid block. Univariate analysis, shows statistically significant association between the type of surgery and anaesthetic technique used $\left(\chi^{2}=22.741, \mathrm{df}=1, \mathrm{p}=0.000\right)$. A statistically significant association was also established between age group of the patients and the anaesthetic technique $\left(\chi^{2}=10.878, \mathrm{df}=2, \mathrm{p}=0.004\right)$. However, there was no statistically significant association between age group of the patients and the type of Caesarean $\operatorname{section}\left(\chi^{2}=0.224, \mathrm{df}=2, \mathrm{p}\right.$ $=0.894)$. Conclusion: The high rate of emergency caesarean intervention has been a persistent denominator in several studies. The root cause of these anomalies such as dearth of expertise at secondary facilities should be addressed. With effective pregnancy supervision, obstetric cases that would end with emergency intervention can be handled electively.
\end{abstract}

Keywords: Caesarean Sections, Magnitude, Northern Nigeria, Pattern, Teaching Hospital

\section{Introduction}

Pregnancy and parturition are physiological processes that mostly end with successful delivery of product of conception through os naturalis. These processes however do not always end this way. In situations where such is not feasible, alternative mode of delivery is employed to reduce risk of maternal and fetal morbidity and/or mortality. Among such modalities is caesarean section which is a surgical procedure for delivering fetus, placenta and membranes, through an abdominal and uterine incision ${ }^{1}$. It has been practiced since antiquity for several reasons ${ }^{2}$. Until the development of asepsis and anaesthesia in the $19^{\text {th }}$ century, Caesarean section was bedeviled with poor outcome for both the mother and the fetus $^{3,5}$.

The safety of this operation has tremendously increased the rate on a global scale but not without attendant complications. The impact on the resources of health care facilities as well as economic, social and psychological burden to individual families and communities involved can be enormous ${ }^{6}$.

The World Health Organization (WHO) recommends that the Caesarean section rate should be $10-15 \%{ }^{7}$. However, there is wide variation of this rate globally as well as locally 8,9

Although elective Caesarean section is considered safer for both mother and fetus, when compared with emergency Caesarean section, the latter continued to exact its dominance in frequency in most health facilities in Nigeria ${ }^{8,9}$. Regional anaesthesia is generally recommended over general anaesthesia in term of safety for both the parturient and the fetus $^{10,11}$. This study is aimed at revealing the magnitude and pattern of Caesarean section at Aminu Kano Teaching Hospital Kano, Nigeria.

\section{Materials and Methods}

Data from operation and anaesthetic registers of pregnant women that had Caesarean section at Aminu Kano Teaching 
Hospital, Nigeria from $1^{\text {st }}$ January2005 to $31^{\text {st }}$ December 2009 were retrieved and information on age, type of operation, whether elective or emergency, and type of anaesthesia used were entered into a personal computer and analyzed using Epi Info statistical software version 3.5.The results were presented in tables; mean, mode and standard deviation were employed where applicable. $\mathrm{X}^{2}$ was used for test of significance. $\mathrm{P}$ value of less than 0.05 was used for test of significance.

\section{Results}

A total of 10,725 vaginal deliveries and 2011 Caesarean operations were done in the department from 2005 - 2009. The Caesarean section rate was $18.75 \%$. The mean age was $28.02 \pm 5.86$ years with the majority of the subjects $(89.73 \%)$ within the age of 18 to 34 years (Table I).

Emergency Caesarian section was the majority 1315 $(65.39 \%)$ while the remaining $696(34.61 \%)$ were elective. General anaesthetic was administered to the majority $1341(66.68 \%)$ of the cases, while $670(33.32 \%)$ had the procedure performed under subarachnoid block (SAB) (Table II).

Univariate analysis, shows statistically significant association between the type of surgery (emergency or elective) and the anaesthetic technique used $\left(\chi^{2}=22.741, \mathrm{df}=\right.$ $1, \mathrm{p}=0.000)$. A statistically significant association was also established between age group of the patients and the type of anaesthesia used $\left(\chi^{2}=10.878, \mathrm{df}=2, \mathrm{p}=0.004\right)$.

However, there was no statistically significant association between age group of the patients and the type of Caesarean section $\left(\chi^{2}=0.224, \mathrm{df}=2\right.$, (Table II)

Table I. Age Group of Patients. Majority of the patients were within the age of 18 to 34 years

\begin{tabular}{lll}
\hline Age Group & Frequency & Percentage (\%) \\
\hline$<18$ & 31 & 1.54 \\
$18-24$ & 729 & 36.25 \\
$25-29$ & 700 & 34.81 \\
$30-34$ & 295 & 14.67 \\
$\geq 35$ & 256 & 12.73 \\
Total & 2011 & 100.00 \\
\hline
\end{tabular}

Table II. Type of Caesarean Section and Anaesthetic technique. Emergency Caesarean section was higher than elective and General anaesthesia was administered more than Subarachnoid block

\begin{tabular}{lll}
\hline Feature & Frequency & Percentages (\%) \\
\hline Caesarean section & & \\
Emergency & 1315 & 65.39 \\
Elective & 696 & 34.61 \\
Total & 2011 & 100.00 \\
Anaesthesia & & \\
GA & 1341 & 66.68 \\
SAB & 670 & 33.32 \\
Total & 2011 & 100.00 \\
\hline
\end{tabular}

$\chi^{2}=22.741, \mathrm{df}=1, \mathrm{p}=0.000$
Table III. Association between Age group and Anaesthetic technique.There was statistically significant association between Age group and Anaesthetic technique

\begin{tabular}{llll}
\hline \multirow{2}{*}{ Age Group (years) } & \multicolumn{2}{l}{ Anaesthetic technique } & Total \\
\cline { 2 - 4 } & GA & SAB & TOTAL \\
\hline$<18$ & 29 & 2 & 31 \\
$18-24$ & 520 & 218 & 738 \\
$25-29$ & 500 & 213 & 713 \\
$30-34$ & 301 & 76 & 377 \\
$\geq 35$ & 86 & 66 & 152 \\
Total & 1436 & 575 & 2011 \\
\hline
\end{tabular}

$\mathrm{GA}=$ General Anaesthesia; $\mathrm{SAB}=$ Subarachnoid block $\mathrm{X}^{2}=10.878, \mathrm{DF}=2, \mathrm{P}=0.004$

Table IV. Age Group and the Type of caesarean section.There was no statistically significant association found between Age group and type of caesarean section

\begin{tabular}{llll}
\hline \multirow{2}{*}{ Age group (years) } & \multicolumn{2}{c}{ Type of C/S } & Total \\
\cline { 2 - 4 } & Emergency & Elective & \\
\hline$<18$ & 18 & 13 & 31 \\
$18-24$ & 498 & 289 & 787 \\
$25-29$ & 357 & 206 & 563 \\
$30-34$ & 293 & 81 & 374 \\
$\geq 35$ & 149 & 107 & 256 \\
Total & 1315 & 696 & 2011 \\
\hline
\end{tabular}

$\mathrm{X}^{2}=0.224, \mathrm{DF}=2, \mathrm{P}=0.894$

\section{Discussion}

The Caesarean section rate, over the period was $18.75 \%$. This was higher than the figures of $9.1 \%, 10.5 \%$ and $11.8 \%$ reported by Ijaiya ${ }^{12}$, Obuna et $\mathrm{al}^{13}$ and Geidam et $\mathrm{al}^{14}$ in Ilorin, Abakaliki and Maiduguri respectively, all in Nigeria. This was also higher than the $10-15.0 \%^{7}$ recommended by the World Health Organization (WHO). This could not be unrelated to the nature of the tertiary hospital as a major referral centre for complicated deliveries within Kano and neighbouring states. More importantly though, the dearth of adequate Obstetricians and Physician Anaesthetists in State owned Health facilities to manage complicated deliveries makes the Federal tertiary health facilities such as ours a hub for referral.

The mean age of the patients was $28.02 \pm 5.86$ SD years which is similar to the finding by Ijaiya et $\mathrm{al}^{12}$ in Ilorin, Nigeria. This could be attributed to the similarity of the two study community being in the northern part of the country and are both predominantly Muslims. Majority of the patients $(85.7 \%)$ were within the ages of $18-34$ years. Geidam ${ }^{14}$ reported high incidence $(52.8 \%)$ of Caesarean section within similar age group. This is mainly due to high fertility rate among this age group and the high fertility rate of the region $^{14}$. Majority of the caesarean sections $(65.4 \%)$ were emergency compared with only $34.6 \%$ of elective Caesarean delivery. Geidam et $\mathrm{al}^{14}$ and Mutihir et $\mathrm{al}^{15}$ reported similar findings. This high rate of emergency Caesarean section could be attributed to the fact that these are tertiary health facilities which serve as referral centres where complicated labours could be managed more effectively. In most cases, the lifesaving CS remains the only choice ${ }^{15}$. Another 
possibility is the dearth of expertise at secondary health facilities in these regions. Therefore, experts that could manage complicated labour are only available at the tertiary health facilities. Up to $66.7 \%$ of the patients had a general anaesthetic. Nwobodo et $\mathrm{al}^{9}$ revealed $53.6 \%$ of the patients that had Caesarean section in Sokoto also had general anaesthesia. This contrasts sharply with the trend in the UK (78\%) and a private hospital based study in Kano, Nigeria $(87 \%)^{16,17}$. Both figures from UK and the private hospital in Kano had all the anaesthetics administered by skilled Physician Anaesthetists. During the period under study, nonphysician anaesthesia providers constituted more than $90 \%$ of the workforce who lacked the skill to perform regional technique, which favoured the general anaesthetic. This brings to fore the need to encourage training of specialist anaesthetists and uphold the existing training program of non-physician anaesthesia providers with requisite skill to perform regional anaesthesia techniques, as stop gap measure in order to bridge the dearth of manpower in primary and secondary health facilities in the country. This will reduce cost of surgical intervention as well as reduce burden of health budget planning for health managers.

In this study there was significant association between the type of surgery, the age group of the patients and the type of anaesthesia $\left(\mathrm{X}^{2}=22.74\right.$ and $10.88 ; \mathrm{P}<0.05$ respectively) but no statistically significant difference between the age group of the patients and the type of Caesarean section.

\section{Conclusion}

The high rate of emergency caesarean intervention has been a persistent denominator in several studies. The root cause of these anomalies such as dearth of expertise at secondary facilities should be addressed. With effective pregnancy supervision, obstetric cases that would end with emergency intervention can be handled electively.

Training of non- physician anaesthesia providers in the provision of subarachnoid block should be encouraged. More importantly, concerted effort should be made to increase the number of Physician anaesthetists to discourage the reliance on general anaesthetic for CS.

These measures will not only reduce the burden of caesarean delivery on health facilities but will also improve outcome and reduce the burden on the individual families and the community.

There is need to conduct a prospective study to look into the root causes of major Obstetric delays in the community in order to find lasting solution to rising caesarean section rate in our community.

\section{References}

[1] Incerpi MH. Operative delivery In: Decherny AH, Nathal L, Goodwin TM, Laufer $\mathrm{N}$ (Eds). Current diagnosis and treatment obstetrics and gynaecology. $10^{\text {th }}$ edn, New York: Mc Graw Hill Companies; 2007.p.465-76
[2] Young JH. Caesarean section: The history and development of the operation from earliest times. London, HK Lewis \& Companies. 1944

[3] Anonymous. Obituary: Sir James Young Simpson. Lancet 1870; i: $715-8$

[4] Anonymous. Obituary: Joseph, Baron Lister. Lancet 1912; i: 465-72

[5] Baskett T. Pioneers in obstetrics and gynaecology6 : James Young Simpson. The Diplomate 1997; 4: 72-3

[6] Gartland MG, taryor VD, Norman AM, Vermund SH. Access to facility delivery and caesarean section in north-central Liberia; a cross-sectional community-based study. BMJ Open 2012; 2: e001602.doi:10.1136/bmjopen-2012-001612

[7] World Health Organization. Appropriate technology for birth. Lancet 1985; 2: 436-7

[8] Obuna JA, Ugboma HAA, Ejike BN, Umeora OUJ, Agwu UM. Pattern and outcome of higher order Caesarean section in a secondary health facility in Nigeria. Research in ObstGynecol 2012; 1 (3): 19-22

[9] Nwobodo EI, Isah AY, Panti A. Elective Caesarean section in a tertiary hospital in Sokoto, Northwestern Nigeria. Niger J Med. 2011; 52(4): 263-5

[10] American society of Anesthesiologists Task Force on obstetric anaesthesia practice guidelines for obstetrics anaesthesia. An updated report by the American Society of Anaesthesiologist Task Force on obstetric anaesthesia. Anaesthesiology 2007; 106: 843-63.doi10.1097/01.anes.0000264744.63275.10

[11] Cyna AM, Dodd J. Clinical update: Obstetric anaesthesia. Lancet 2007; 370:642.doi10.1016/s0140-6736(07)61320-8

[12] Ijaiya MA, Aboyeji PA. Caesarean delivery: The trend over a ten year period at Ilorin, Nigeria. Nig J Surg Res. 2001; 3(1): $42-9$

[13] Obuna JA, Ugboma HAA, Ejikeme BN, Umeora OUJ, Agwu UM. Pattern and outcome of higher order Caesarean section in a secondary health facility in Nigeria. Research $\begin{array}{llll}\text { ObstetGynaecol 2012; } & 1(3) \text { : } & 19-22 & \text { DOI: }\end{array}$ $10.5923 / \mathrm{j} \cdot \operatorname{rog} 20120103.01$

[14] Geidam AD, Audu BM, Kawuwa BM, Obed TY. Rising trend and indications of Caesarean section at the university of Maiduguri Teaching Hospital, Nigeria. Ann Afr Med 2009; 8:127-32

[15] Mutihir JT, Daru PH, Ujah IAO. Elective Caesarean sections at the Jos University Teaching Hospital. Trop J Obstet Gynecol 2005; 22(1): 39-41

[16] Shibli KU, Russell IF. A survey of anaesthetic techniques used for caesarean section in the UK in 1997. Int J ObstetAnesth 2000; 9: 160-7

[17] Galadanci HS, Mohammed AD, Atiku M, Habeeb MM, Danjuma M, Ibrahim SA. Safety and acceptability of spinal anaesthesia for caesarean section in Kano, Nigeria. Oral presentation $49^{\text {th }}$ WACS annual conference 